\title{
Management of anterior inferior cerebellar artery aneurysms: an illustrative case and review of literature
}

\author{
Nicholas C. Bambakidis, M.D., ${ }^{1}$ Sunil Manjila, M.D., ${ }^{1}$ Shervin Dashti, M.D., ${ }^{2}$ \\ Robert Tarr, M.D., ${ }^{3}$ and Cliff A. Megerian, M.D. ${ }^{4}$ \\ ${ }^{1}$ Department of Neurological Surgery, University Hospitals Case Medical Center, Cleveland, Ohio; \\ ${ }^{2}$ Division of Neurosurgery, Barrow Neurological Institute, Phoenix, Arizona; and Departments of \\ ${ }^{3}$ Neuroradiology and ${ }^{4}$ Otolaryngology-Head and Neck Surgery, University Hospitals Case Medical Center, \\ Cleveland, Ohio
}

\begin{abstract}
Aneurysms of the anterior inferior cerebellar artery (AICA) are relatively rare among intracranial aneurysms. They can occur in 1 of 3 regions of the AICA: 1) craniocaudal (high or low riding), 2) mediolateral-premeatal (proximal), and 3) meatal-postmeatal (distal). The management strategies for treatment differ according to the location and configuration of the aneurysm. The existing body of neurosurgical literature contains articles published on aneurysms arising from the AICA near the basilar artery (BA), intracanalicular/meatal aneurysms, and distal AICA. Several therapeutic options exist, encompassing microsurgical and endovascular techniques. The authors describe a case of treatment involving a large BA-AICA aneurysm approached via exposure of the presigmoid dura using a retromastoid suboccipital craniectomy and partial petrosectomy. Treatment of these lesions requires detailed knowledge of the anatomy, and an anatomical overview of the AICA with its arterial loops and significant branches is presented, including a discussion of the internal auditory (labyrinthine) artery, recurrent perforating arteries, subarcuate artery, and cerebellosubarcuate artery. The authors discuss the various surgical approaches (retromastoid, far lateral, subtemporal, and transclival) with appropriate illustrations, citing the advantages and disadvantages in accessing these AICA lesions in relation to these approaches. The complications of these different surgical techniques and possible clinical effects of parent artery occlusion during AICA surgery are highlighted. (DOI: 10.3171/2009.1.FOCUS0915)
\end{abstract}

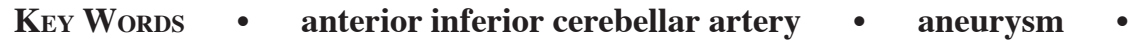 surgical approaches}

$\mathrm{T}$ He AICA arises in the CPA, commonly from the lower one-third of the BA. It is surrounded by a dense collection of critical neurovascular structures, including the lower cranial nerves and nearby brainstem perforators (Fig. 1). Aneurysms arising from the AICA are relatively rare, accounting for $<2 \%$ of all intracranial aneurysms. ${ }^{18}$ As with posterior circulation aneurysms in general, surgical treatment options are often limited by the narrow angles of approach available for the cerebrovascular surgeon, the presence of brainstem perforators, the deep location of critical neurovascular anatomy, and difficulty in accessing adequate proximal control. The rarity of AICA aneurysms results in limited experience in treating these lesions, even in large tertiary care centers. Evolving endovascular treatments add to the breadth of available management options, making a review of these lesions timely.

Abbreviations used in this paper: $\mathrm{AICA}=$ anterior inferior cerebellar artery; $\mathrm{BA}=$ basilar artery; $\mathrm{CPA}=$ cerebellopontine angle; $\mathrm{CN}=$ cranial nerve; $\mathrm{DS}=$ digital subtraction; IAM = internal acoustic meatus; $\mathrm{PICA}=$ posterior inferior cerebellar artery; $\mathrm{SCA}=$ superior cerebellar artery.

\section{Case Report}

History and Examination. A 58-year-old woman presented with a 6-month history of progressive headaches and dizziness. The results of physical examination were unremarkable. There were no cerebellar signs or motor/sensory deficits. A digital subtraction angiogram of the cerebral circulation demonstrated a $10-\mathrm{mm}$, rightsided AICA aneurysm beginning $1 \mathrm{~cm}$ distal to the vessel origin from the BA (Fig. 2). The supratentorial arterial system was found to be normal, with good filling across the circle of Willis.

Because of the narrow caliber of the AICA in this patient, the sharp angle of its takeoff from the BA, and the aneurysm's large size with possible thrombus, surgical treatment was recommended.

Operation and Postoperative Course: Step I. A right retrosigmoid incision was made after infiltration of the area with $1 \%$ lidocaine and 1:100,000 epinephrine. This incision was extended anteriorly, and subperiosteal flaps were raised to expose the spine of Henley as well as the root of the zygoma and the mastoid tip. A standard mas- 


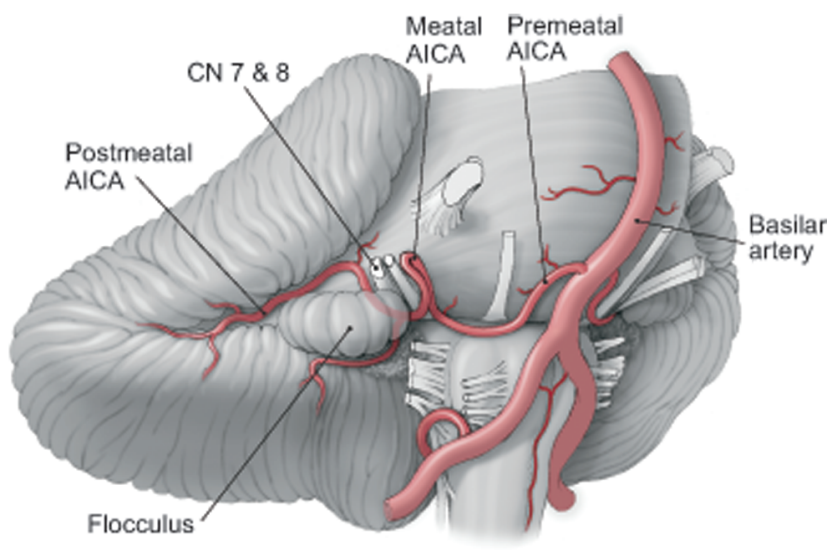

FIG. 1. The AICA exits the BA and travels through the CPA. From Dashti et al., Vascular lesions of the cerebellopontine angle, in Bambakidis NC, Megerian C, Spetzler RF (eds): Surgery of the Cerebellopontine Angle, BC Decker, 2009. Reprinted with permission from Barrow Neurological Institute.

toidectomy was performed, followed by the skeletonization of the sigmoid sinus, sinodural angle, posterior fossa dura, and osseous posterior canal wall. The horizontal semicircular canal was identified and preserved, whereas the facial nerve was skeletonized. After removing the mastoid tip, diamond drills were used on the retrosigmoid area to expose the dura behind the sigmoid sinus and to transect the mastoid emissary vein and cauterize it. Bone removal was then performed from over the sigmoid sinus area and the middle fossa, along with the sinodural angle, with exposure of the greater petrosal sinus. The bone was removed to the level of the posterior semicircular canal and the superior semicircular canal. At this point, the sigmoid sinus could be mobilized and completely exposed to facilitate the removal of the retromastoid suboccipital bone.

Operation and Postoperative Course: Step II. Baseline somatosensory evoked potentials were monitored after induction of general anesthesia. After retrosigmoid craniectomy, the dura was opened in a curvilinear fashion. The sigmoid sinus was retracted to the ear, allowing exposure of the right CPA. A self-retaining retractor was used to relax the cerebellar hemisphere. A lumbar drain for CSF drainage was placed to assist brain relaxation. The CN VII-VIII complex was identified and carefully protected, exposing the large proximal AICA aneurysm, which was very broad-necked. Microdissection was carried around the aneurysm until 2 titanium clips were placed across the base of it, isolating it from the circulation (Video).

VIDEO: Intraoperative video showing microdissection carried around the aneurysm until 2 titanium clips are placed across the lesion's base, isolating it from the circulation. Click to view with Windows media player.

Limiting factors were the deep corridor, narrow angle of view, and persistent high aneurysm turgor because of difficulty obtaining proximal control and temporary clip occlusion. Indocyanine green videoangiography was used

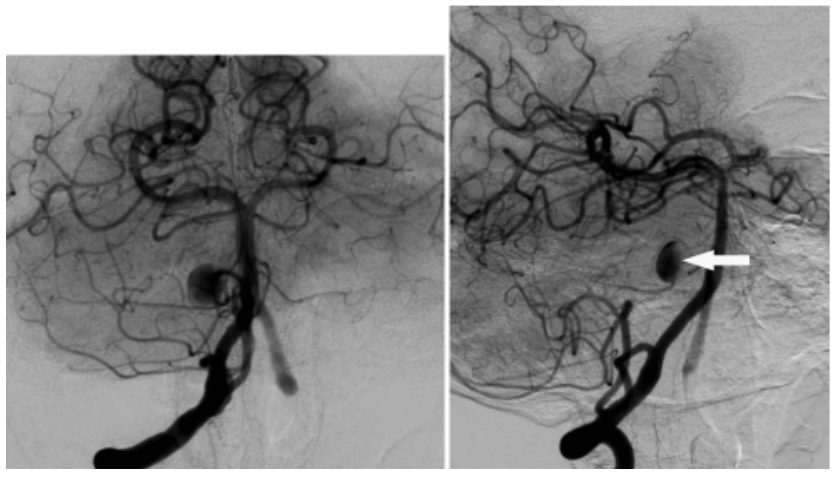

FIG. 2. Vertebral artery injection angiograms, anteroposterior (left) and lateral (right) views, demonstrating the presence of a large right AICA aneurysm. Note the presence of only partial opacification of the aneurysm, indicating the presence of luminal thrombus (arrow).

to confirm excellent proximal and distal flow of the AICA vessel. Papaverine was applied around the acoustic-vestibular complex, and the dura was closed primarily. A fat patch was used to close the mastoidectomy using 4-0 nylon covered with Duragen and Tisseel fibro-nerve sealant. Finally, a titanium mesh cranioplasty was performed to cover a 4.5 -cm-diameter craniectomy. The patient experienced transient postoperative lower-motor-neuron $\mathrm{CN}$ VII paresis and an ipsilateral CN VI paresis. Postoperative angiography showed no evidence of residual aneurysm, although there was evidence of occlusion of the AICA (Fig. 3) considered the result of slow-flow through the parent vessel at the time of surgical clipping, lead-

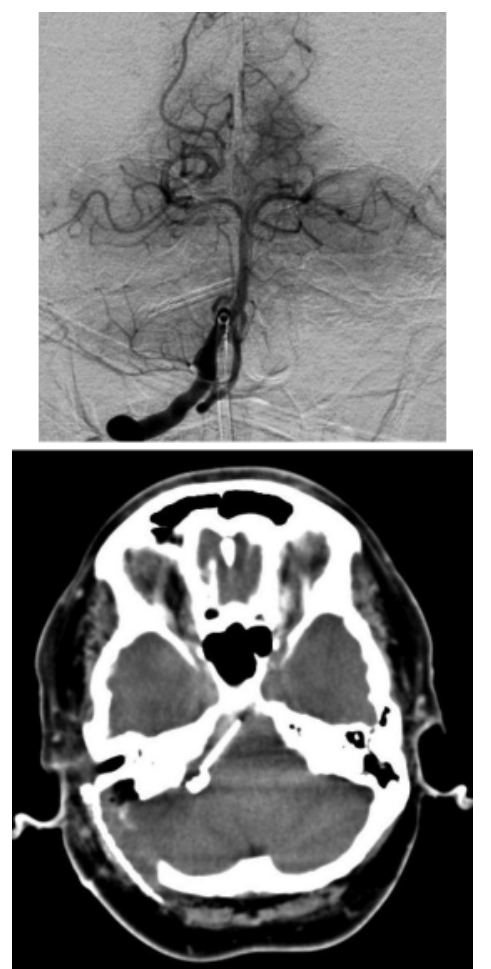

FIG. 3. Upper: Postoperative angiogram demonstrating complete obliteration of the aneurysm with absent filling of the AICA. Lower: Postoperative CT scan showing the extent of osseous removal and the size and location of the aneurysm clip. 


\section{Management of AICA aneurysms}

TABLE 1: Proposed classification of AICA aneurysms*

\begin{tabular}{|c|c|c|}
\hline Location & New Classification & Rhoton Classification \\
\hline $\begin{array}{l}\text { proximal (aneurysms arising from the } \\
\text { AICA origin to the meatal loop) }\end{array}$ & $\begin{array}{l}\text { vertebrobasilar junction, AICA-PICA origin } \\
\text { premeatal segment (CPA) }\end{array}$ & $\begin{array}{l}\text { corresponds to anterior pontine segment } \\
\text { corresponds to LPS-premeatal }\end{array}$ \\
\hline middle (meatal loop) & $\begin{array}{l}\text { Type I (aneurysms on the loop, not in the IAM) } \\
\text { Type II (partially in the IAM) } \\
\text { Type III (fully in the IAM) }\end{array}$ & $\begin{array}{l}\text { LPS-premeatal } \\
\text { LPS-meatal } \\
\text { LPS-meatal }\end{array}$ \\
\hline $\begin{array}{l}\text { distal (aneurysms arising from the } \\
\text { end of the meatal loop to the distal } \\
\text { AICA) }\end{array}$ & postmeatal & flocculopeduncular \& cortical segments \\
\hline
\end{tabular}

ing to progressive thrombosis. The patient's postoperative course was otherwise uneventful, with no evidence of cerebellar signs on examination and no significant abnormalities on postoperative imaging (Fig. 3).

\section{Discussion}

Aneurysms of the AICA are exceedingly rare and presentations vary. ${ }^{24,31,40,51}$ In a series of more than 3500 saccular aneurysms treated surgically during a 16-year period, Gonzalez and colleagues ${ }^{19}$ reported that a mere $34(1.7 \%)$ aneurysms arose from the AICA. Of these, 21 became symptomatic with subarachnoid hemorrhage. Of the 13 unruptured aneurysms, 7 manifested with brainstem compression. Eight aneurysms were giant $(>2.5$ $\mathrm{cm})$. Incidences of peripheral AICA aneurysms on dorsolateral and caudomedial branches of the same vessel have been reported. ${ }^{4}$ Zager and colleagues ${ }^{63}$ have described a patient with a ruptured meatal loop aneurysm in whom 3 prior negative DS angiograms had shown no positive findings. Iwanga and associates ${ }^{27}$ have described a peripheral aneurysm that was diagnosed on CT angiography but was previously undetected on 2 DS angiograms; the aneurysm eventually bled. Menovsky and colleagues ${ }^{37}$ have reported on AICA aneurysms in association with high-flow lesions, such as arteriovenous malformations fed by the AICA. They performed a lateral retromastoid suboccipital craniectomy and aneurysm clipping, and followed this with the removal of the draining veins. The authors also reported a case of hemangioblastoma associated with AICA aneurysms. Recent publications on case series of distal AICA aneurysms represent postmeatal segments treated surgically or endovascularly, with or without occlusion of the parent artery.

The course of the parent AICA artery is intimately related to the pons, foramen of Luschka, middle cerebellar peduncle, and petrosal surface of the cerebellum. After its origin from the BA, the AICA wraps around the pons near CN VI-VIII and then sends branches to the internal acoustic meatus and choroid plexus of Luschka. The artery then passes around the flocculus on the middle cerebellar peduncle to supply the lips of the cerebellopontine fissure and the petrosal surface. It commonly bifurcates near the CN VII-VIII complex to form rostral and caudal trunks. The AICA gives rise to perforators to the brainstem and choroidal branches to the tela and choroid plexus, as well as giving rise to unique branches, such as recurrent perforators and the internal auditory and subarcuate artery.

\section{Segments of the AICA: Implications in Management of Aneurysms}

Aneurysms of the AICA can be categorized into 3 types: proximal, meatal, and distal (Table 1). Proximal aneurysms arise from the BA-AICA junction or at the premeatal segment, AICA bifurcation, or combined AICA-PICA origin. Meatal aneurysms arise from the meatal loop or segment and are subclassified as Type I, II, or III, based on Yamakawa and colleagues' classification. ${ }^{62}$ The classification depends on the location of the aneurysm with respect to the IAM, which in turn determines the extent of IAM drilling. In Type I ("remote") lesions, an aneurysm exists on the vascular loop outside the meatus, and is most common (56\% of cases) in the CPA/proximal part of the lateral pontine segment; in Type II ("plugged") lesions, the aneurysm is partly buried in the IAM, with the neck of the aneurysm located to one side; and in Type III ("buried") lesions, the aneurysm is entirely contained by the IAM. Types II and III are collectively called intracanalicular AICA aneurysms. The surgical implication of these aneurysms lies in the fact that the buried aneurysms are very difficult to treat without extensive drilling of the IAM. Distal AICA aneurysms usually arise from the rostral postmeatal branch.

\section{Management Options for AICA Aneurysms}

Surgical Approaches. Depending on the anatomical features of the aneurysm, various skull base approaches, including the retrosigmoid, far-lateral, middle fossa, transcochlear, translabyrinthine, orbitozygomatic, and combined supratentorial-infratentorial presigmoid approaches, are being used to manage AICA aneurysms. The common surgical approaches for AICA aneurysms that are discussed in the literature include the retromastoid suboccipital approach with or without petrosectomy (posterolateral), the subtemporal middle fossa approach (lateral), the pterional or orbitozygomatic approach (anterolateral), and, rarely, the anterior approach (transclival transfacial).

The unique difficulty associated with clipping AICA aneurysms partially reflects their location near the skull 


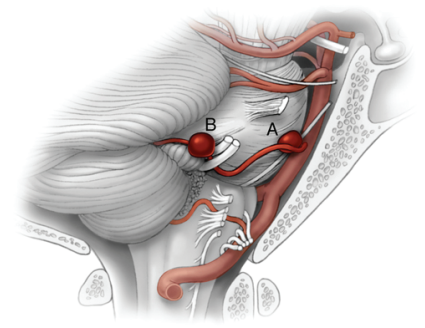

FIG. 4. Artist's rendition. Lateral view of the CPA in which the AICA aneurysm is seen to arise from the premeatal segment of the vessel $(A)$. A distal AICA aneurysm arises from the postmeatal segment between CN VII and VIII (B). From Dashti et al., Vascular lesions of the cerebellopontine angle, in Bambakidis NC, Megerian C, Spetzler RF (eds): Surgery of the Cerebellopontine Angle, BC Decker, 2009. Reprinted with permission from Barrow Neurological Institute.

base and their proximity to multiple CNs. The 2 most important factors in choosing a surgical approach are (a) the craniocaudal location of the aneurysm in relation to the clivus and (b) the mediolateral location, along with the course of the artery (Fig. 4). The development of an adequate corridor between the petrous temporal bone and CPA is critical to adequate visualization of the AICA. High-riding aneurysms may be reached by the orbitozygomatic approach, although using this approach is limited by the need to perform a posterior clinoidectomy (Fig. 5). This may increase complications related to the approach, particularly $\mathrm{CN}$ paresis. An alternate method that may be selected for high-riding AICA aneurysms would be a subtemporal middle fossa approach with division of the tentorium combined with a petrosectomy. The subtemporal corridor was popularized by Drake and colleagues, ${ }^{14}$ who described its use in the exposure of 32 AICA aneurysms. A limitation of this approach is that it may not offer adequate visualization of the AICA origin. As the AICABA aneurysm points anteriorly in most cases, the neck is grasped by forceps and the sac is tipped away during the dissection, defining the pontine segment. ${ }^{25,43,58,60}$ Spetzler used the subtemporal and subtemporal-transtentorial approach only once in the surgical treatment of 41 AICA aneurysms and cited a significant rate of morbidity associated with its use..$^{18}$ As a result, it is primarily used in the approach of midclival aneurysms. In addition to the removal of the petrous apex, the use of the subtemporaltranstentorial approach involves opening the tentorial edge, increasing the extent of exposure, and posing a hazard to CN IV, which travels along the tentorial edge. Recent cadaveric studies have not demonstrated an increase in surgical freedom or quantitative exposure to the ventral brainstem and origin of the AICA when comparing the subtemporal-transtentorial approach to the retrosigmoid approach. ${ }^{8}$

The retrosigmoid route affords the greatest versatility in terms of approaches while being the simplest and most straightforward way in which to expose the AICA region. This approach is commonly used for removal of CPA tumors, such as acoustic schwannomas, and microdecompression of AICA branches in hemifacial spasm. ${ }^{9} 13,20,30,34,35,38,64$ As performed in our case, skeletonization and lateral retraction of the transverse-sigmoid junction allows for minimal cerebellar retraction. If additional exposure is desired, a partial petrosectomy may be performed with the opening of the presigmoid dura. While the sigmoid sinus may be sacrificed, this is often unnecessary. Sequential movement of the operating mi-
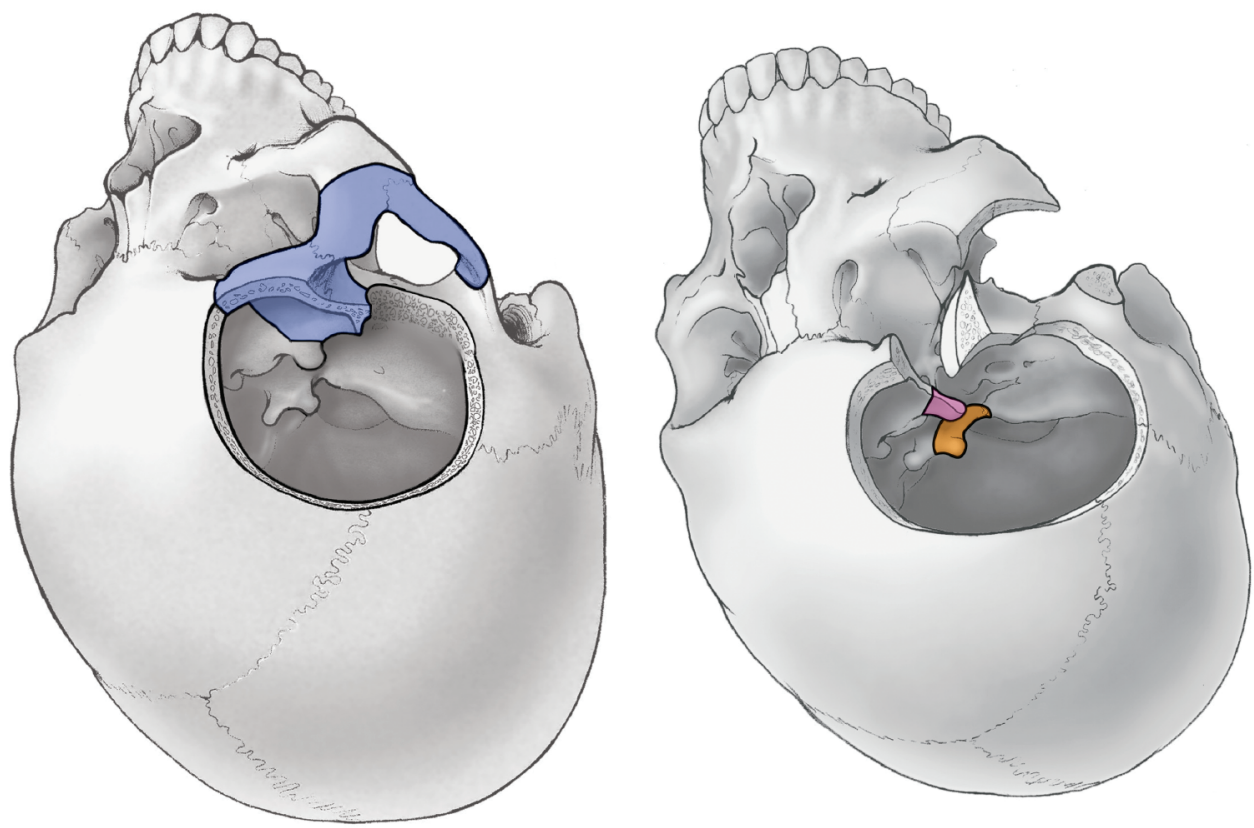

FIG. 5. Artist's drawings. Left: High-riding AICA aneurysms may be accessed using the orbitozygomatic approach. The lateral wall of the orbit and the zygomatic arch (blue) are removed. Right: Often the anterior clinoid process (pink) and posterior clinoid process (orange) must be drilled away to provide adequate exposure to the upper BA and AICA. From Dashti et al., 2009, Vascular lesions of the cerebellopontine angle, in Bambakidis NC, Megerian C, Spetzler RF (eds): Surgery of the Cerebellopontine Angle, BC Decker, 2009. Reprinted with permission from Barrow Neurological Institute. 


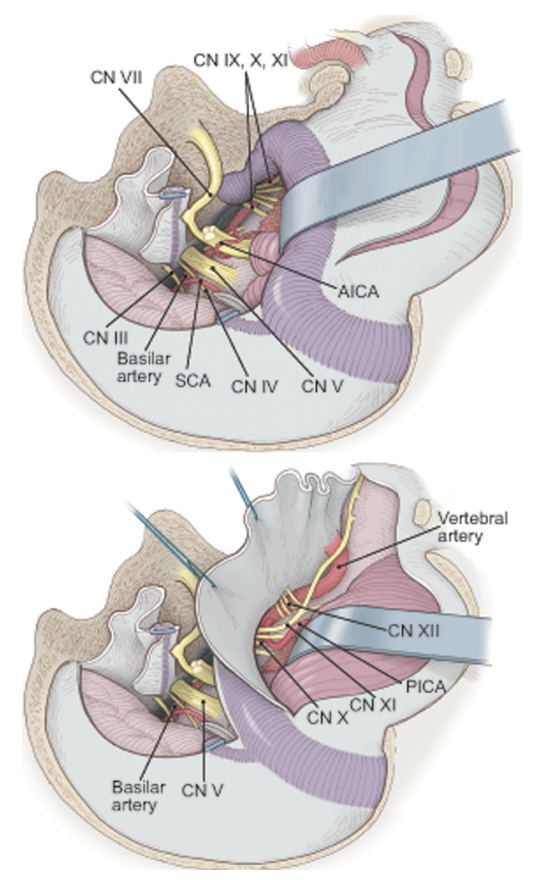

FIG. 6. Artist's illustrations. The posterior fossa contents are illustrated following combined approaches to the CPA. The degree of petrosectomy determines the degree of exposure and may be as limited or extensive as desired. Judicious retraction of the sigmoid sinus and sequential movement of the operating microscope, posteriorly (upper) or anteriorly (lower), affords a view that is nearly as complete as that provided by its division. Use of this strategy minimizes the risk of venous injury or infarction. $\mathrm{CN} \mathrm{III} \mathrm{=} \mathrm{occulomotor} \mathrm{nerve;} \mathrm{CN} \mathrm{IV} \mathrm{=} \mathrm{trochlear} \mathrm{nerve;}$ $\mathrm{CN} \mathrm{V} \mathrm{=} \mathrm{trigeminal} \mathrm{nerve;} \mathrm{CN} \mathrm{VII} \mathrm{=} \mathrm{facial} \mathrm{nerve;} \mathrm{CN} \mathrm{IX} \mathrm{=} \mathrm{glossopharyn-}$ geal nerve; $\mathrm{CN} \mathrm{X}$ = vagus nerve; $\mathrm{CN} \mathrm{XI}=$ spinal accessory nerve; $\mathrm{CN}$ $\mathrm{XII}=$ hypoglossal nerve. From Bambakidis et al., Combined surgical approaches, in Bambakidis NC, Megerian C, Spetzler RF (eds): Surgery of the Cerebellopontine Angle, BC Decker, 2009. Reprinted with permission from Barrow Neurological Institute.

croscope combined with judicious use of the retractor allow for adequate visualization of the CPA while minimizing the risk of venous injury or infarction (Fig. 6). ${ }^{6}$ The premeatal AICA can then be seen between CN VI and CN VII. During subsequent dissection, care must be taken because it is easy to injure CN VI. The retrosigmoid approach offers good access to distal AICA aneurysms off the meatal and postmeatal segments, the lateral aspect of the mid- and lower brainstem below $\mathrm{CN} \mathrm{V}$, and the area near the IAM. The retrosigmoid approach can be combined with either a medial petrosectomy in highriding aneurysms or a far-lateral approach when required to expose low-lying aneurysms near the vertebrobasilar junction. Such combined skull base approaches are particularly helpful in the surgical clipping of giant AICA aneurysms. ${ }^{11,19}$

Transpetrosal approaches (transcochlear and translabyrinthine) provide the most direct route to the brainstem. ${ }^{29,53,56,59}$ However, these approaches are associated with significant morbidity, such as deafness, facial nerve palsy, and CSF leakage, and they are rarely performed in the absence of giant AICA aneurysms. ${ }^{5}$ Rhoton ${ }^{46}$ compared the middle fossa and translabyrinthine approaches to the AICA and found notable differences. In the middle fossa approach to the IAM, only a short segment of the artery near the meatus is exposed and, often, only if the artery loops into the meatal porus. The translabyrinthine approach exposes the AICA at and for a short distance proximal and distal to the IAM and along the anterior part of the petrous surface. An obvious drawback of the translabyrinthine approach is its association with permanent hearing loss.

The supratentorial-infratentorial presigmoid approach allows various degrees of resection involving the semicircular canals, vestibule, and cochlea. Transoraltransfacial approaches to AICA aneurysms have been reported but are not routinely used because of their high rates of associated morbidity. ${ }^{10,12,26,41,49,52}$

Protection of the cerebellum and brainstem is achieved by several neuroprotective methods, and the $\mathrm{CNs}$ are protected by judicious use of intraoperative monitoring. Hypothermic cardiac arrest with barbiturate cerebral protection is an important adjunct for surgery of BA and AICA aneurysms. ${ }^{55}$ Adequate deflation of the aneurysm during this technique allows further dissection of the dome away from the brainstem and minimizes the risks of intraoperative hemorrhage.

Although rare, dissecting aneurysms involving the AICA have been reported. ${ }^{22}$ Generally, these lesions present with brainstem ischemic symptoms and may be suggested on MR imaging by an evolution of signal characteristics, lesion shrinkage over time, and angiographic evidence of fusiform dilation with luminal irregularities. High-flow lesions, such as arteriovenous malformations, often occur with AICA aneurysms, complicating the choice of surgical approach.,17,32,33,44,45,61 Such lesions can be treated using surgery or endovascular therapy in multiple stages as a patient's clinical condition warrants.

Endovascular Options. The treatment of posterior circulation aneurysms has undergone significant changes as endovascular treatment options have evolved. ${ }^{21,25,47,54}$ Because these options eliminate surgical approach-related morbidity, they are particularly appropriate for consideration in the treatment of AICA aneurysms. Requirements of successful coil embolization are an adequate aneurysm dome-to-neck ratio and the ability to maneuver a microcatheter into the dome of the aneurysm. Because most AICA aneurysms arise proximally, microcatheter navigation into the aneurysm dome is often feasible. Occasionally, complete obliteration of the aneurysm sac is impossible without jeopardizing parent vessel patency due to protruding coil loops. Nevertheless, it is clear that coil embolization is a valuable treatment option, often considered first-line management for these lesions. ${ }^{15,36,42,47,54,57}$

The indications for endovascular treatment of distal AICA aneurysms are less clear. Not more than 10 reported cases of endovascularly treated distal AICA aneurysms appear in the literature, and a common theme in these reports is that parent artery occlusion is necessary to achieve adequate aneurysm obliteration. ${ }^{11,57}$ Saito and colleagues ${ }^{48}$ reported that only 58 patients had AICA aneurysms in the meatal or postmeatal segments. In their report of 3 cases, 2 patients underwent surgical trap- 
ping and the remaining patient underwent endovascular coiling due to poor clinical condition..$^{50}$ An increase in hearing disturbance was noted in 2 patients, one in either modality of treatment. Dissection as a consequence of embolization has been described and often results in a subarachnoid hemorrhage with an intraventricular extension.

Advances in endovascular techniques have led to increased treatment of even giant AICA aneurysms. ${ }^{47,54}$ In such cases, balloon-assisted techniques with stents placed across the neck of an aneurysm are valuable tools when the aneurysmal dome-to-neck ratio is unfavorable. The need for antiplatelet agents in cases requiring stent augmentation increases the risk of hemorrhagic complications; however, it limits the utility of such techniques in cases in which aneurysms have presented in association with a subarachnoid hemorrhage. In cases of large aneurysms that cannot be safely and directly occluded, flow reversal leading to aneurysm thrombosis may be induced following direct vertebral artery or BA occlusion with detachable coils. Such maneuvers are not undertaken lightly because they are associated with significant rates of ischemic complications, and balloon test occlusion should be performed first to identify patients who can tolerate permanent vessel occlusion. ${ }^{11}$ In some cases, flow augmentation may be considered via distal extracranial-intracranial bypass.

\section{Parent Artery Occlusion in AICA Aneurysms: a Safe Option?}

The case illustrated in our report underscores some of the challenges inherent in managing difficult lesions. Despite attempts to the contrary, the patency of the distal AICA was compromised by surgical treatment, and it may be argued that endovascular management would have been equally effective in treating this particular lesion. In an attempt to preserve hearing, an extensive labyrinthectomy was not performed, although this would have increased the surgical exposure. Sigmoid sinus sacrifice would have afforded additional exposure, but this was not performed because of the large size of the sinus on the affected side without comparably sized contralateral venous drainage. Despite sacrifice of the AICA, there were no associated clinical signs, likely a reflection of the small size of the parent vessel and presence of collateral flow from the posterior cerebral artery and SCA. Although endovascular treatment could have been attempted, AICA canalization would have been hazardous and would not have resulted in complete aneurysm obliteration. However, such assumptions are controversial and highly dependent on institutional biases and the comfort level of the treating physicians with various therapies. Although the initial goal of treatment was preservation of the parent vessel, which influenced the initial decision regarding the recommended treatment modality, clearly endovascular treatment would have offered a potentially equivalent outcome. Such difficulties highlight the challenges inherent in treating these rare lesions.

The occlusion of the AICA can result in syndromes characterized by 4 distinct clinical presentations that are strikingly different from PICA or SCA infarcts. The most common clinical presentation is the classic syndrome described by Adams, which includes vertigo, nausea, vomiting, dysarthria, and tinnitus. ${ }^{1}$ Ipsilateral facial palsy, facial sensory loss, and Horner's syndrome are often observed. Other possible deficits are appendicular dysmetria, contralateral loss of sensation, hearing loss, conjugate lateral gaze palsy, dysphagia, and, in advanced cases, ipsilateral motor weakness. Because several of these signs are similar to Wallenberg syndrome, some may confuse this condition with a PICA infarction. The second most common form is isolated vertigo, often confused with labyrinthitis. Amarenco and colleagues ${ }^{3}$ have shown that the vertigo in cases of AICA infarction results from damage to the flocculus, whereas in cases of PICA infarction it is due to a damaged nodulus. A third form in which the patient typically presents with coma, ophthalmoplegia, and quadriplegia is often fatal. A fourth form of AICA infarction, in which the patient presents with minimal cerebellar signs, is probably explained by the adequate collateral circulation from other cerebellar arteries. Suzuki and colleagues ${ }^{57}$ have proposed that the AICA could be sacrificed distal to the internal auditory branch because of anastomotic connections with branches of the PICA and the SCA. Hansen ${ }^{23}$ has demonstrated that anastomotic vessels from the carotid circulation via the temporal bone can supply blood to the cochlea and labyrinth, but the adequacy of these anastomotic vessels is extremely difficult to assess intraoperatively and during cerebral angiography. Rhoton ${ }^{46}$ has reported that the size of the infarction area after AICA occlusion is inversely related to the size of the PICA and the SCA as well as to the extent of anastomoses with these vessels. For example, if the PICA is unusually small and the AICA is large, the collateral circulation is likely to be poor, creating an unfavorable environment in the event of AICA occlusion at surgery.

Akar and colleagues ${ }^{2}$ have reported that the branches of the AICA that supply the inferior part of the olive arise 3-18 mm distal to the origin of the AICA, although AICA occlusion causes a lateral inferior pontine syndrome. They have argued that the obstruction of the AICA distal to the internal auditory artery should not produce cerebellar deficits due to anastomoses with PICA branches to the hemisphere. Likewise, Nishimoto and colleagues ${ }^{39}$ have attributed the high incidence of CN VII and VIII dysfunction to the ischemic damage, whereas Fisch ${ }^{16}$ has described rami nervosum from the internal auditory artery being involved in the vascularization of the CN VIIVIII complex. Andaluz and colleagues ${ }^{4}$ have argued that CN VII and VIII palsies can result from vascular injury despite anatomical preservation of the nerve during surgery. A CN VI deficit is relatively uncommon because the nerve is slack as it courses up to gain access to the cavernous sinus and is easily displaced from the neck of the AICA aneurysm.

The exposure of large AICA aneurysms treated with multiple clip applications can be confining. At the critical moment of clip application, the anatomy will be obscured by the clip applicator and clip handle in the surgical field. The occlusion of the BA and perforators often leads to catastrophic consequences, and these can be prevented 
by verifying the clip position during and after application. Endoscopic assistance may be an option in certain instances, allowing visualization of otherwise hidden anatomical regions. ${ }^{28}$

\section{Conclusions}

Proximal or vertebrobasilar AICA aneurysms lie in a confined narrow space in the prepontine cistern, and several surgical approaches are designed to allow a direct line of sight down the posterior slope of the petrous bone and clivus, from a supratentorial or infratentorial exposure. Distal AICA aneurysms are less favorable lesions for endovascular therapy because of difficulty in navigating catheters and are often best treated surgically. However, coil embolization is preferred in advanced age and poor clinical status of patients with AICA aneurysms. The illustrative case underscores the inherent difficulties of treating these deeply located and rare lesions.

\section{References}

1. Adams RD: Occlusion of the anterior inferior cerebellar artery. Arch Neurol Psychiatry 49:765-770, 1943

2. Akar ZC, Dujovny M, Gomez-Tortosa E, Slavin KV, Ausman JL: Microvascular anatomy of the anterior surface of the medulla oblongata and olive. J Neurosurg 82:97-105, 1995

3. Amarenco P, Lévy C, Cohen A, Touboul PJ, Roullet E, Bousser MG: Causes and mechanisms of territorial and nonterritorial cerebellar infarcts in 115 consecutive patients. Stroke 25:105-112, 1994

4. Andaluz N, Pensak ML, Zuccarello M: Multiple, peripheral aneurysms of the anterior inferior cerebellar artery. Acta Neurochir (Wien) 147:419-422, 2005

5. Bambakidis NC, Kakarla UK, Kim LJ, Nakaji P, Porter RW, Daspit CP, et al: The evolution of surgical approaches in the treatment of petroclival meningiomas: a single-center retrospective review. Operative Neurosurgery 61:202-211, 2007

6. Bambakidis NC, Safavi-Abbasi S, Spetzler RF: Combined surgical approaches, in Bambakidis NC, Megerian C, Spetzler RF (eds): Surgery of the Cerebellopontine Angle. Hamilton, Ontario: BC Decker Publishers, 2009

7. Brown RD Jr, Wiebers DO, Forbes GS: Unruptured intracranial aneurysms and arteriovenous malformations: frequency of intracranial hemorrhage and relationship of lesions. J Neurosurg 73:859-863, 1990

8. Chang SW, Wu A, Gore P, Beres E, Porter RW, Preul MC, et al: Quantitative comparison of Kawase's approach versus the retrosigmoid approach: implications for tumors involving both the middle and posterior fossae. Neurosurgery, in press, 2009

9. Chung SS, Chang JH, Choi JY, Chang JW, Park YG: Microvascular decompression for hemifacial spasm: a long-term follow-up of 1,169 consecutive cases. Stereotact Funct Neurosurg 77:190-193, 2001

10. Crockard HA, Koksel T, Watkin N: Transoral transclival clipping of anterior interior cerebellar artery aneurysm using new rotating applier. Technical note. J Neurosurg 75:483-485, 1991

11. Dashti SR, Miller JP, Tarr RW, Selman WR: Vascular lesions of the cerebellopontine angle, in Bambakidis NC, Megerian C, Spetzler RF (eds): Surgery of the Cerebellopontine Angle. Hamilton, Ontario: BC Decker Publishers, 2009

12. de Ios Reyes RA, Kantrowitz AB, Detwiler PW, Feghale JG, Hall CD, Sonstein WJ.: Transoral-transclival clipping of a giant lower basilar artery aneurysm. Surg Neurol 38:379-382, 1992
13. Drake CG, Friedman AH, Peerless SJ: Posterior fossa arteriovenous malformations. J Neurosurg 64:1-10, 1986

14. Drake CG, Peerless SG, Hernesniemi JA: Surgery of Vertebrobasilar Aneurysms: London, Ontario Experience on 1767 Patients. New York: Springer, 1996

15. Eckard D, O'Boynick P, McPherson C, Eckard VR, Han P, Arnold P, Batnitzky S: Coil occlusion of the parent artery for treatment of symptomatic peripheral intracranial aneurysms. AJNR Am J Neuroradiol 21:137-142, 2000

16. Fisch U: The surgical anatomy of the so-called internal auditory artery, in Hamberger CA, Wersall J (eds): Disorders of the Skull Base Region Proceedings. New York: Wiley Interscience Division, 1969, pp 121-130

17. Gibson RM, Melo AN: Angiographic ending of an aneurysm and arteriovenous malformation in the posterior cranial fossa in a case of subarachnoid hemorrhage. Neurosurg Psychiatry 23:237-238, 1960

18. Gonzalez LF, Alexander MJ, McDougall CG, Spetzler RF: Anterioinferior cerebellar artery aneurysms: surgical approaches and outcomes: a review of 34 cases. Neurosurgery 55:1025-1035, 2004

19. Gonzalez LF, Amin-Hanjani S, Bambakidis NC, Spetzler RF: Skull base approaches to the basilar artery. Neurosurg Focus 19:E3, 2005

20. Goto Y, Matsushima T, Natori Y, Inamura T, Tobimatsu S: Delayed effects of the microvascular decompression on hemifacial spasm: a retrospective study of 131 consecutive operated cases. Neurol Res 24(2):296-300, 2002

21. Gruber A, Killer M, Bavinzski G, Richling B: Clinical and angiographic results of endovascular coiling treatment of giant and very large intracranial aneurysms: a 7-year, single-center experience. Neurosurgery 45:793-803, 1999

22. Hancock JH, Millar JS: Spontaneous dissection of the anterior inferior cerebellar artery. Neuroradiology 42:535-538, 2000

23. Hansen CC: Vascular anatomy of the human temporal bone: a preliminary report. Ann Otol Rhinol Laryngol 79:269-273, 1970

24. Harnsberger HR: Vascular loop compression, CPA-IAC, in Osborn AG, Blaser SI, Slazman KL, et al (eds): Diagnostic Imaging: Brain, ed 2. Salt Lake City: Amirsys, 2004, pp 24-27

25. Hassan T, Ezura M, Takahashi A: Treatment of giant fusiform aneurysms of the basilar trunk with intra-aneurysmal and basilar artery coil embolization. Surg Neurol 62:455-462, 2004

26. Hitchcock E, Cowie R: Transoral-transclival clipping of a midline vertebral artery aneurysm. Neurosurg Psychiatry 46:446-448, 1983

27. Iwanaga S, Shrier DA, Okawara SH, Namaguchi Y: Value of $\mathrm{CT}$ angiography in the evaluation of a peripheral anterior inferior cerebellar artery aneurysm: case report. Clin Imaging 23:77-80, 1999

28. Kalavakonda C, Sekhar LN, Ramachandran P, Hechl P: Endoscope-assisted microsurgery for intracranial aneurysms. Neurosurgery 51:1119-1126, 2002

29. Kawase T, Toya S, Shiobara R, Mine T: Transpetrosal approach for aneurysms of the lower basilar artery. J Neurosurg 63:857-861, 1985

30. Kim Y, Tanaka A, Kimura M, Yoshinaga S, Tomonaga M: Arteriovenous malformation in the cerebellopontine angle presenting as hemifacial spasm: case report. Neurol Med Chir (Tokyo) 31:109-112, 1991

31. Kohna D, Kowney LL, Lim J, Cohen NL, Elowitz E: Uncommon lesions presenting as tumors of the internal auditory canal and cerebellopontine angle. Am J Otol 18:386-392, 1997

32. Kondziolka D, Nixon BJ, Lasjaunias P, Tucker WS, TerBrugge $\mathrm{K}$, Spiegel SM: Cerebral arteriovenous malformations with 
associated arterial aneurysm: hemodynamic and therapeutic considerations. Can J Neurol Sci 15:130-134, 1988

33. Lasjaunias P, Piske R, Terbrugge K, Willinsky R: Cerebral arteriovenous malformations (C. AVM) and associated arterial aneurysms (AA). Analysis of $101 \mathrm{C}$. AVM cases, with 37 AA in 23 patients. Acta Neurochir (Wien) 91:29-36, 1988

34. Lawton MT, Daspit CP, Spetzler RF: Transpetrosal and combination approaches to skull base lesions. Clin Neurosurg 43:91-112, 1996

35. Linskey ME, Jannetta PJ, Martinez AJ: A vascular malformation mimicking an intracanalicular acoustic neurilemoma Case report. J Neurosurg 74:516-519, 1991

36. Lubicz B, Leclerc X, Gauvrit JY, Lejeune JP, Pruvo JP: Endovascular treatment of peripheral cerebellar artery aneurysms. AJNR Am J Neuroradiol 24:1208-1213, 2003

37. Menovsky T, Andre Grotenhuis J, Bartels RH: Aneurysm of the anterior inferior cerebellar artery (AICA) associated with high-flow lesion: report of two cases and review of literature. J Clin Neurosci 9:207-211, 2002

38. Nagata S, Fujii K, Nomura T, Matsushima T, Fukui M, Yasumori K: Hemifacial spasm caused by CP angle AVM associated with ruptured aneurysm in the feeding artery: case report. Neurol Med Chir (Tokyo) 31:406-409, 1991

39. Nishimoto A, Fujimoto S, Tsuchimoto S, Matsumoto Y, Tabuchi K, Higashi T: Anterior interior cerebellar artery aneurysm. Report of three cases. J Neurosurg 59:697-702, 1983

40. Neimat JS, Hoh BL, McKenna MJ, Rabinov JD, Ogilvy CS: Aneurysmal expansion presenting as facial weakness: case report and review of the literature. Neurosurgery 56:190, 2005

41. Ogilvy CS, Barker FG, Joseph MP, Cheney ML, Swearingen B, Crowell RM: Transfacial transclival approach for midline posterior circulation aneurysms. Neurosurgery 39:736-741, 1996

42. Okumura Y, Sakaki T, Hirabayashi H, Shimomura T: Intrameatal aneurysm successfully treated by meatal loop trapping: case report. Neurol Med Chir (Tokyo) 39:161-164, 1999

43. Omahen DA, Findlay JM: A giant fusiform basilar aneurysm treated by bilateral vertebral artery occlusion. J Clin Neurosci 11:324-328, 2004

44. Perata HJ, Tomisick TA, Tew JM Jr: Feeding artery pedicle aneurysms: association with parenchymal hemorrhage and arteriovenous malformation in the brain. J Neurosurg 80:631634, 1994

45. Redekop G, TerBrugge K, Montanera W, Willinsky R: Arterial aneurysms associated with cerebral arteriovenous malformations: classification, incidence, and risk of hemorrhage. J Neurosurg 89:539-546, 1998

46. Rhoton AL: The cerebellar arteries, in Apuzzo MLJ (ed): Rhoton's Anatomy: Cranial Anatomy and Surgical Approaches. Schaumburg, IL: Lippincott Williams and Wilkins, 2003, pp 461-500

47. Ross IB, Weill A, Poitin M, Moret J: Endovascular treatment of distally located giant aneurysms. Neurosurgery 47:11471152,2000

48. Saito A, Ezura M, Takahashi A, Yoshimoto T: An arterial dissection of the distal anterior inferior cerebellar artery treated by endovascular therapy. No Shinkei Geka 28:269-274, 2000

49. Saito I, Takahashi H, Joshita H, Usui M, Sasaki T, Sano K: Clipping of vertebrobasilar aneurysms by the transoral trans- clival approach. Neurol Med Chir (Tokyo) 20:753-758, 1980

50. Saito R, Tominaga T, Ezura M, Shimizu H, Yoshimoto T: Distal anterior inferior cerebellar artery aneurysms: report of three cases and literature review. No Shinkei Geka 29:709714, 2001

51. Sarkar A, Link MJ: Distal anterior inferior cerrebellar artery aneurysm masquerading as a cerebellopontine angle tumor: case report and review of literature. Skull Base 14:101-106, 2004

52. Seifert V: Direct surgery of basilar trunk and vertebrobasilar junction aneurysms via the combined transpetrosal approach. Neurol Med Chir (Tokyo) 38:86-92, 1998

53. Seifert V, Stolke D: Posterior transpetrosal approach to aneurysms of the basilar trunk and vertebrobasilar junction. J Neurosurg 85:373-379, 1996

54. Sluzewski M, Menovsky T, van Rooij WJ, Wijnalda D: Coiling of very large or giant cerebral aneurysms: long-term clinical and serial angiographic results. AJNR Am J Neuroradiol 24:257-262, 2003

55. Spetzler RF, Hadley MN, Rigamonti D, Carter LP, Raudzens PA, Shedd SA, et al: Aneurysms of the basilar artery treated with circulatory arrest, hypothermia, and barbiturate cerebral protection. J Neurosurg 68:868-879, 1988

56. Steward DL, Pensak ML: Transpetrosal surgery techniques. Otolaryngol Clin North Am 35:367-391, 2002

57. Suzuki K, Meguro K, Wada M, Fujita K, Nose T: Embolization of a ruptured aneurysm of the distal anterior inferior cerebellar artery: case report and review of the literature. Surg Neurol 51:509-512, 1999

58. Tersaka S, Itamoto K, Houkin K: Basilar trunk aneurysm surgically treated with anterior petrosectomy and external carotid artery-to-posterior cerebral artery bypass: technical note. Neurosurgery 51:1083-1087, 2002

59. Tummala RP, Coscarella E, Morcos JJ: Transpetrosal approaches to the posterior fossa. Neurosurg Focus 19 (2):E6, 2005

60. Ubogu EE, Chase CM, Verrees MA, Metzger AK, Zaidat OO: Cervicomedullary junction compression caused by vertebral artery dolichoectasia and requiring surgical treatment. Case report. J Neurosurg 96:140-143, 2002

61. Verbiest H: Arterial and arteriovenous aneurysms of the posterior fossa. Psychiatr Neurol Neurochir 65:329-369, 1962

62. Yamakawa H, Hattori T, Tanigawara T, Sahashi Y, Ohkuma A: Intracanalicular aneurysm at the meatal loop of the distal anterior inferior cerebellar artery: a case report and review of literature. Surg Neurol 61:82-88, 2004

63. Zager EL, Shaver EG, Hurst RW, Flamm ES: Distal anterior inferior cerebellar aneurysms. Report of four cases. J Neurosurg 97:692-696, 2002

64. Zhao W, Shen J, Pu C: Microvascular decompression for hemifacial spasm: experience of 215 cases. Zhonghua Yi Xue Za Zhi 81:1121-1123, 2001

Manuscript submitted January 14, 2009.

Accepted February 11, 2009.

Address correspondence to: Nicholas C. Bambakidis, M.D., c/o Kim Duvall, Editorial Manager, Department of Neurological Surgery, University Hospitals Case Medical Center, 11100 Euclid Avenue, Cleveland, Ohio 44106. email: Nicholas.Bambakidis@ uhhospitals.org. 